\title{
Continuous fixed-bed studies for adsorptive remediation of phenol by garlic peel powder
}

\author{
P. Muthamilselvi ${ }^{1} \cdot$ R. Karthikeyan ${ }^{2} \cdot$ Ashish Kapoor $^{1} \cdot$ S. Prabhakar ${ }^{1}$
}

Received: 7 July 2018 / Accepted: 20 December 2018 / Published online: 29 December 2018

(c) The Author(s) 2018

\begin{abstract}
In the quest for eco-friendly and cost-effective adsorbents for the removal of phenol from aqueous systems, garlic peel has been identified as a potential candidate in our earlier study. In the current investigations, we have studied the performance of garlic peel powder in packed fixed-bed column, to assess its potential for real-time deployment for remediation of phenolcontaminated aqueous effluents. Accordingly, parametric studies were carried out with reference to feed concentration, bed height, and flow rate. The experiments indicated the suitability of garlic peel powder-packed columns for remediation of phenol present in aqueous effluents. Salient observations include the improvement of adsorption and remediation efficiency at lower feed flow rates. The assessment of the experimental data using different theoretical models indicated the applicability of Yoon-Nelson model for the adsorption of phenol by garlic peel powder.
\end{abstract}

Keywords Phenol $\cdot$ Garlic peel $\cdot$ Adsorption $\cdot$ Column $\cdot$ Aqueous effluent $\cdot$ Remediation

\section{Introduction}

Water contamination by phenolic substances is of increasing concern in recent years due to their high toxicity and potential accumulation in the ecological cycle. Phenols find their way into natural water bodies from a variety of sources including effluents from several industries such as polymers, rubber, disinfectants, drugs, fine chemicals, as well as domestic sewage, agricultural run-offs, and chemical spillage [1]. In view of the detrimental effects of phenol exposure on living entities, it is imperative to treat the discharge streams containing phenol before disposal. Several techniques have been investigated for the remediation of phenol and its derivatives from wastewater streams including distillation, solvent extraction, adsorption, and coagulation besides biological processes [2,3]. All these processes offer varying degrees of success in the removal of phenol from waste streams. Among these, adsorption process is preferred

P. Muthamilselvi

muthamilselvi2016@gmail.com

1 Department of Chemical Engineering, SRM Institute of Science and Technology, Kattankulathur, Tamil Nadu, India

2 Anjalai Ammal Mahalingam Engineering College, Kovilvenni, Tamil Nadu, India because of its simplicity in operation, flexibility in design, and easy scalability of capacity $[4,5]$. Commercially available activated carbon (AC) is an established and widely used adsorbent for the removal of a variety of contaminants, particularly organic species. However, the regeneration of the saturated activated carbon is quite tedious and cumbersome besides being significantly expensive. This calls for locating and developing low-cost adsorbents [6-8], particularly, based on natural materials. Many natural materials such as silt, clay, zeolites, food, and agricultural wastes (fruit seeds, coconut coir pith, bagasse, etc.) and waste products from industries (fly ash, bottom ash, red mud, sludge, etc.) have been investigated for the removal of a variety of pollutants $[9,10]$. The process for large-scale adoption for the treatment of discharge streams containing phenol has to be ecofriendly, simple to operate and economically affordable. Considering the fact that the pollutant should not alone be removed, but should be rendered harmless on the disposal of the adsorbed species, we were looking for waste agricultural produces, which are normally bio-degradable. 'Garlic peel' (GP) is a commonly obtainable agro-waste product in most parts of the world. Garlic peel has been used as an adsorbent for the remediation of environmental contaminants, including dyes and heavy-metal species [11]. It is a natural bio-fiber comprising primarily of cellulose, hemicellulose, and pectic components. Various functional groups present in 
these components, including amino, hydroxyl, and carboxyl groups, possibly assist in bond formation with phenol molecules [12]. In this context, it was considered appropriate to study the removal of phenol from aqueous streams using garlic peel as an adsorbent. Adsorption is a simple technique particularly when operated in a once-through mode without regeneration and the spent material is bio-degradable. Unlike activated carbon, garlic peels are much cheaper and hence offsets the advantage of reuse. Spent garlic peels can be easily disposed into the environment, as it bio-degradable including the adsorbed phenol.

Our earlier batch studies with garlic peels have established significant uptake of phenol from aqueous media [13]. Field deployment requires continuous removal of phenol for a predefined volume in a column before its exhaustion. After establishing the behavioral characteristics of the phenol on the column mode, the performance of the system with reference to real effluents has to be established. Real effluents would have different contaminants, besides phenol depending on the source. As the composition of each stream would be unique, individual systems have to be studied to assess the extent of phenol removal. Accordingly, in this paper, we have confined our studies only to pure phenol-water system with a subsequent plan to take up the phenol containing effluent streams one by one, as it requires industrial interaction.

The peel is easy to handle and process, besides being biodecomposable. In our earlier work, we have demonstrated the preparation of garlic peel as a sorbent material and its efficacy in phenol removal in batch studies. The design and development of field deployable adsorption units require a continuous phenol removal system. Fixed-bed vertical columns akin to activated carbon systems containing the adsorbent material would satisfy the requirement. Hence, the current study focuses on the investigation of phenol removal in a continuous fixed-bed adsorption column from aqueous solution stream employing garlic peel powder (GPP). The work is designed to assess the column performance by varying the operating parameters, namely, flow rates, influent phenol concentration, and packed bed column height and hence to provide the basic data for scale up. An attempt has been made to assess the data based on the different mathematical models published in the literature.

\section{Materials and methods}

\section{Preparation of sorbent}

Garlic peels were collected from the dry kitchen waste from students' hostel of SRM Institute of Science and Technology, Kattankulathur campus. The peels were manually segregated from the other vegetable and fruit peels. Segregated peels were washed first with normal tap water and later rinsed with distilled water before drying in an electric oven at $45{ }^{\circ} \mathrm{C}$ to crispness and preserved in a desiccator. The garlic peelings thus conditioned were crumpled and pulverized using a well-washed grinding machine to avoid any chance of contamination. The crushed material was sieved and classified to obtain particle size in the desired range. The resultant garlic peel powder was stored in dry air-tight plastic containers for further use. The material was used as such in sorption experiments without any further processing or treatment. The garlic peel powder characteristics have already been reported [13] and a brief summary of important characteristics is mentioned here. GPP used in these experimental studies are found to have moisture content $2.69 \%$, volatile matter $68.54 \%$, ash $7.67 \%$, and fixed carbon $21.12 \%$. $\mathrm{pH}_{\mathrm{zpc}}$ (pH at point of zero charge) is 3.9 with a surface area of $1.34425 \mathrm{~m}^{2} / \mathrm{g}$ (BET) and average particle size of $250 \mu \mathrm{m}$ diameter.

\section{Preparation of adsorbate}

Phenol (analytical grade) was purchased from SISCON, India. Distilled water was utilized for preparing the stock aqueous phenolic solution of $1000 \mathrm{ppm}$ concentration. The concentration of the stock solution was standardized using titrimetric method [14] and was stored in amber-colored bottles. Portions of the stock solution were used in preparing different phenol concentrations for use in the experiments by appropriate dilution to the required extent.

\section{Fixed-bed adsorption column}

Figure 1 shows the schematic diagram of the experimental set up used for column studies. The column is made up of an acrylic tube of $3 \mathrm{~cm}$ internal diameter and $58 \mathrm{~cm}$ length with flanges on either end with provisions for inlet and outlet. The dimensions have been chosen to accommodate about 3-10 $\mathrm{g}$ of the adsorbent. The large length of the column enables to facilitate the studies with varying bed lengths. Glass beads of $1.5 \mathrm{~mm}$ diameter were packed at the bottom of the column for support. The column is filled with known weight of the garlic peel powder to ensure setting up of the requisite column height in tune with the experimental design. As the purpose was to find out the impact of varying bed heights on phenol adsorption with the other parameters being held constant, three heights were chosen as 5, 10, and 15. The masses of GPP sorbent packed in the column were $3.220 \mathrm{~g}$ (for $5 \mathrm{~cm}$ ), $6.410 \mathrm{~g}$ (for $10 \mathrm{~cm}$ ), and $9.234 \mathrm{~g}$ (for $15 \mathrm{~cm}$ ). Similarly, the flow rates were also varied between 15 and $25 \mathrm{~mL} / \mathrm{min}$ to maintain the linear velocities from 2 to $3.5 \mathrm{~cm} / \mathrm{min}$ and initial phenol concentrations from 50 to $150 \mathrm{mg} / \mathrm{L}$. In a normal experiment, the synthetic solution of phenol and water was pumped through a peristaltic pump 


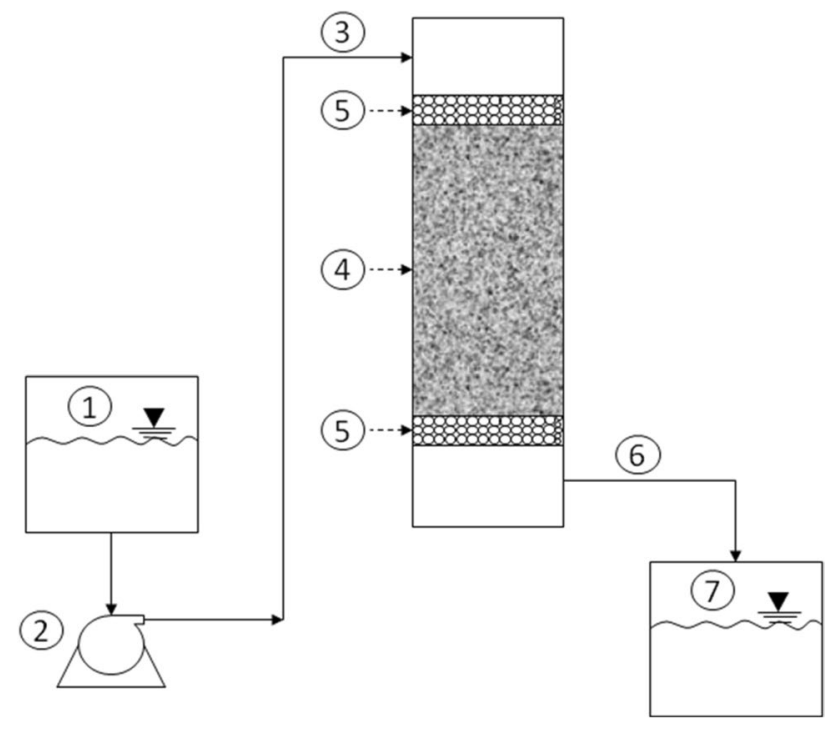

Fig. 1 Experimental set up of the packed bed column. (1) Synthetic phenol effluent tank, (2) peristaltic pump, (3) feed inlet, (4) packed sorbent, (5) sorbent support, (6) treated effluent outlet, (7) treated effluent collection tank

at a predetermined flow rate through the top of the column. Samples were collected from the outlet stream of the column as a function of time. Phenol concentrations were estimated following the procedure indicated below.

\section{Estimation of phenol concentration}

Phenol concentration in aqueous solutions was determined using the spectrophotometric method (Agilent Cary 60 $\mathrm{UV}-\mathrm{Vis}$ Spectrophotometer) based on the reaction of phenolic species with 4-amino antipyrine (4-AAP) in the presence of potassium ferricyanide. Accordingly, $2 \mathrm{~g}$ of 4-aminoantipyrine was dissolved in distilled water and the volume made up to $100 \mathrm{~mL}$. A solution of potassium ferricyanide was prepared by dissolving $8 \mathrm{~g}$ of the salt in $100 \mathrm{~mL}$ of distilled water. $2 \mathrm{~mL}$ of $\mathrm{NH}_{4} \mathrm{Cl}-\mathrm{NH}_{4} \mathrm{OH}$ buffer solution was added to each $50 \mathrm{~mL}$ sample of phenol solution and mixed thoroughly. $2 \mathrm{~mL}$ of potassium ferricyanide solution was then added to the mixture and left for approximately 15 min to allow complete color development. The maximum absorbance for phenolic solutions in spectrophotometer was observed at $510 \mathrm{~nm}$. Calibration plot was prepared using the standard concentrations of phenol and was found to be linear with $R^{2}$ value of 0.99 . Phenol concentrations of unknown samples were estimated by measuring the absorbance and using the calibration plot.

Based on the experimental data obtained from the parametric studies (flow rate, bed height, and concentration), the breakthrough curves were plotted for the normalized concentration of phenol with respect to time. Normalized concentration $\left(C_{t} / C_{0}\right)$ is dimensionless number and corresponds to the exiting concentration $\left(C_{t}\right)$ at time $t$ as a fraction of initial concentration $\left(C_{0}\right)$. The effluent volume $V_{\text {eff }}$ (in $\mathrm{mL}$ ) was calculated using Eq. (1):

$V_{\text {eff }}=Q t_{\text {total }}$,

where $Q$ denotes the liquid stream volumetric flow rate in the column $\left(\mathrm{mL} \mathrm{min}^{-1}\right)$ and $t_{\text {total }}$ is the aggregate time in minutes.

The total mass of phenol sorbed by the garlic peel powder $q_{\text {total }}(\mathrm{mg})$ for a predetermined initial feed composition and a fixed volumetric flow rate was estimated using the integral expression Eq. (2) and is equivalent to the net area underlying the breakthrough curve:

$q_{\text {total }}=\frac{Q}{1000} \int_{t=0}^{t=\text { total }} C_{\mathrm{R}} \mathrm{d} t$,

where $C_{\mathrm{R}}=\left(C_{0}-C_{t}\right)$ between zero and time $t$.

The entire mass of phenol fed to the packed bed $m_{\text {total }}$ (mg) was ascertained using Eq. (3):

$m_{\mathrm{total}}=\frac{C_{0} Q t_{\mathrm{total}}}{1000}$

The total phenol removal $(\% R)$ was determined by finding the ratio of the amount of phenol adsorbed $\left(q_{\text {total }}\right)$ to the entire phenol quantity supplied to the column $\left(m_{\text {total }}\right)$ with the help of the following relation Eq. (4):

$\% R=\frac{q_{\text {total }}}{m_{\text {total }}} \times 100$.

The quantity of phenol adsorbed at the equilibrium conditions or sorption capacity $q_{\mathrm{e}}$ [mass of sorbed phenol (mg)/ mass of sorbent $(\mathrm{g})]$ and the phenol concentration at equilibrium $C_{\mathrm{e}}(\mathrm{mg} / \mathrm{L})$ were assessed using Eqs. (5) and (6), respectively:

$q_{\mathrm{e}}=\frac{q_{\mathrm{total}}}{m}$,

where $m$ denotes the quantity of sorbent in grams:

$C_{\mathrm{e}}=\left(\frac{m_{\mathrm{total}}-q_{\mathrm{total}}}{V_{\mathrm{eff}}}\right) \times 100$.

Empty Bed Contact Time (EBCT) signifies the time of interaction between solid phase (adsorbent) and solution phase. EBCT (min) is a crucial design variable and is used to determine the critical bed dimensions and sorbent contact time. Empty bed contact time was estimated using the following relation between packed bed volume $V(\mathrm{~L})$ and liquid stream flow rate $Q(\mathrm{~mL} / \mathrm{min})$ :

$\mathrm{EBCT}=\frac{V}{Q}$ 


\section{Influence of operating parameters}

The effect of three operating parameters, namely, volumetric flow rate, feed (initial) phenol concentration, and bed height, was studied. Volumetric flow rates relate to the effective contact time between sorbate and sorbent in the column, thus influencing the mass transfer rate. Three distinct volumetric flow rates $(15,20$, and $25 \mathrm{~mL} / \mathrm{min})$ for a preset bed height $(15 \mathrm{~cm})$ and constant feed composition in aqueous stream $(50 \mathrm{mg} / \mathrm{L})$ were studied. Initial concentration of phenol in the feed stream governs the rate of mass transport. The effect of initial concentration of phenol was evaluated at 50 and $150 \mathrm{mg} / \mathrm{L}$ in successive experiments, at a constant bed height $(15 \mathrm{~cm})$ and constant volumetric flow rate $(15 \mathrm{~mL} /$ min). Bed height is a crucial determinant which governs the capacity and life of an adsorption column which are required for successful deployment in the field. Experiments were carried out for three different bed heights, namely, 5, 10, and 15 , maintaining the volumetric flow rate at $15 \mathrm{~mL} / \mathrm{min}$ with an initial phenol concentration of $50 \mathrm{mg} / \mathrm{L}$ in the incoming stream.

\section{Models of continuous column adsorption studies}

\section{Thomas model}

Thomas model is an extensively used adsorption model that assumes fluid flow behavior in the packed bed is analogous to plug flow without any axial mixing. Irrespective of early or delayed breakthrough conditions, the model assumes Langmuir adsorption equilibrium conditions and obeys reversible second-order reaction kinetics. The model is apt in cases, where the sorption process is independent of exterior surface and pore diffusion considerations [15]. The quantitative version of the model is given by Eq. (8):

$\ln \left(\frac{C_{0}}{C_{t}}-1\right)=\frac{K_{\mathrm{Th}} q_{\mathrm{e}} m}{Q}-K_{\mathrm{Th}} C_{0} t$,

where $K_{\mathrm{Th}}(\mathrm{mL} / \mathrm{min} \mathrm{mg})$ denotes the Thomas constant, $q_{\mathrm{e}}$ $(\mathrm{mg} / \mathrm{g})$ is the adsorption capacity, $C_{0}(\mathrm{mg} / \mathrm{L})$ is the influent solution composition, $C_{t}(\mathrm{mg} / \mathrm{L})$ is the outlet solution concentration, $m(\mathrm{~g})$ is the mass of sorbent in the column, and $t(\min )$ is the time. The values of $K_{\mathrm{Th}}$ and $q_{\mathrm{e}}$ were estimated from the linear plot.

\section{Yoon-Nelson model}

Yoon-Nelson model assumes that as the adsorption proceeds, the probability of adsorption for every subsequent species decreases [16]. The model is independent of physical and chemical characteristics of the system. The mathematical expression of the model is $\ln \left(\frac{C_{t}}{C_{0}-C_{t}}\right)=K_{\mathrm{YN}} t-\tau_{\mathrm{cal}} K_{\mathrm{YN}}$

where $K_{\mathrm{YN}}(\mathrm{L} / \mathrm{min})$ designates the rate constant and $\tau_{\text {cal }}$ (min) is the time duration required for half of adsorbate to achieve breakthrough.

\section{Clark model}

Clark model assumes the applicability of the Freundlich isotherm of adsorption behavior with the overall sorption rate being determined by the mass transfer consideration outside the adsorbate [17]. The mathematical expression of the model is

$\ln \left[\left(\frac{C_{0}}{C_{t}}\right)^{n-1}-1\right]=r t+\ln A$,

where $r\left(\mathrm{~min}^{-1}\right)$ and $A$ are Clark constants. The model can be used to estimate additional parameters, namely, sorption rate constant $(k)$ and sorbate removal capacities $\left(q\right.$ and $\left.q_{m}\right)$ using $r$ and $A$ values, using the following equations:

$\ln A=\frac{Z k q}{u_{0}}$

$q_{m}=\frac{q V}{m}$

$r=k C_{0}$.

The linear velocity $u_{0}$ is calculated from volumetric flow rate and column cross-sectional area data. $Z$ is the bed height, $V$ is the packed bed volume and $m$ is the quantity of adsorbate used.

\section{Adams-Bohart model}

The Adams-Bohart model hinges upon the surface reaction mechanism and states that the rate of adsorption of adsorbate molecules varies in direct proportion to the adsorption capacity available on the surface of the adsorbent. [18]. The expression of the model is

$\ln \frac{C_{t}}{C_{0}}=K_{\text {Adams }} C_{0} t-K_{\text {Adams }} N_{0} \frac{Z}{u_{0}}$,

where $K_{\text {Adamas }}(\mathrm{L} / \mathrm{min} \mathrm{mg})$ denotes the Adams-Bohart model rate constant, $N_{0}(\mathrm{mg} / \mathrm{L})$ designates the maximum species adsorptive capacity per unit volume of the column, $Z$ is the column height, and $u_{0}$ is the influent stream linear velocity. 


\section{Wolborska model}

The Wolborska model describes adsorption behavior on the basis of diffusive mass transport phenomena for low concentration phase of breakthrough plots. The mathematical representation of the Wolborska model [19] is

$\ln \frac{C_{t}}{C_{0}}=\frac{\beta C_{0}}{N_{0}} t-\frac{\beta Z}{u_{0}}$,

where $\beta$ is the kinetic coefficient of external mass transport $\left(\mathrm{min}^{-1}\right)$. All the other parameters are the same as in the Adams-Bohart model described earlier.

Continuous fixed-bed adsorption column design requires the estimation of concentration data with respect to time from the breakthrough curves. In this work, phenol sorption behavior using garlic peel powder (GPP) adsorbent was studied by applying thermodynamic models, including Thomas, Yoon-Nelson, Clark, Adams-Bohart, and Wolksbora model to the experimental data.

\section{Fitness of the adsorption models}

The error analysis was performed to obtain the best fitting model using the coefficient of determination $\left(R^{2}\right)$ and sum

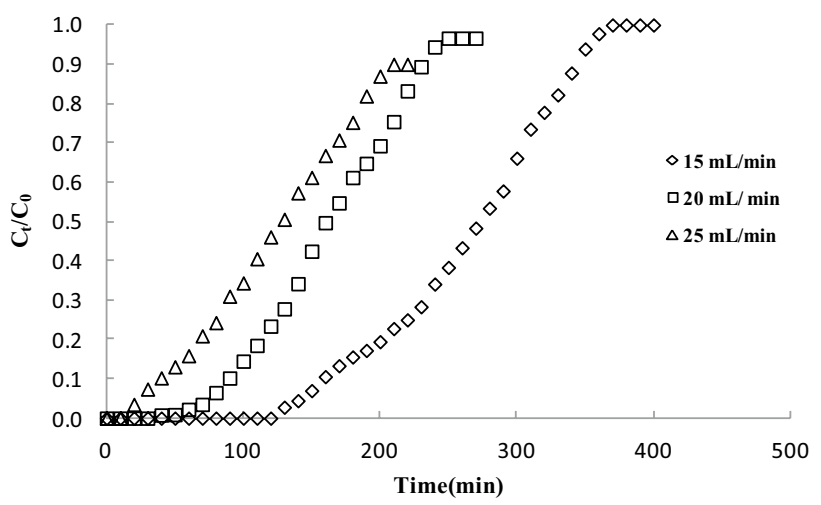

Fig. 2 Effect of flow rate on the breakthrough curve. (Operating conditions: phenol concentration $50 \mathrm{mg} / \mathrm{L}, \mathrm{pH} 2$, bed height $15 \mathrm{~cm}$ ) of the squared differences between the experimental data set and predicted values obtained from the aforementioned models. The following expression gives the sum of the squares of error (SSE):

$\mathrm{SSE}=\frac{\sum\left\{\left(\frac{C_{t}}{C_{0}}\right)_{\mathrm{c}}-\left(\frac{C_{t}}{C_{0}}\right)_{\mathrm{e}}\right\}^{2}}{N}$,

where $\left(\frac{C_{t}}{C_{0}}\right)_{\mathrm{c}}$ is the predicted value for the ratio of effluent and influent phenol composition and $\left(\frac{C_{t}}{C_{0}}\right)_{\mathrm{e}}$ is the experimentally determined value for the ratio of effluent and influent phenol composition in the streams. $N$ denotes the total number of experimental data points.

\section{Results and discussion}

\section{Influence of flow rate on sorption performance}

The uptake of phenol by garlic peel powder was studied at three different volumetric flow rates: 15,20 , and $25 \mathrm{~mL} / \mathrm{min}$ to examine the impact of flows on the sorption bed performance. For the experimental studies, the initial phenol concentration in the feed stream was maintained at $50 \mathrm{mg} / \mathrm{L}$ and the bed height used was $15 \mathrm{~cm}$. The breakthrough time $\left(t_{\mathrm{b}}\right)$ and the exhaust time $\left(t_{\mathrm{e}}\right)$ corresponded to the concentration ratios $\frac{c_{t}}{c_{0}}=0.10$ and 0.90 , respectively. The respective breakthrough volume $\left(V_{\mathrm{b}}\right)$ and exhaust volume $\left(V_{\mathrm{e}}\right)$ data were determined using the volumetric flow rate. Figure 2 shows the breakthrough curves for all the three volumetric flow rates. The instant breakthrough time decreased with increasing flow rate. Accordingly, the instant breakthrough time observed was 160,90 , and 40 min corresponding to the volumetric flow rates of 15,20 , and $25 \mathrm{~mL} / \mathrm{min}$, respectively, and the exhaust times were 340, 230, and 200 min, respectively. At the break through point, the amount of phenol adsorbed for the same initial concentration of $50 \mathrm{mg} / \mathrm{L}$ corresponded to $120 \mathrm{mg}, 90 \mathrm{mg}$, and $50 \mathrm{mg}$, while at exhaustion, the amounts adsorbed were $255 \mathrm{mg}, 230 \mathrm{mg}$, and $250 \mathrm{mg}$. The

Table 1 Column data and their parameters obtained at different bed heights, flow rates and influent phenol concentration onto GPP

\begin{tabular}{|c|c|c|c|c|c|c|c|c|c|c|c|}
\hline$Z(\mathrm{~cm})$ & $Q(\mathrm{~L} / \mathrm{min})$ & $C_{0}(\mathrm{mg} / \mathrm{L})$ & $t_{\mathrm{b}}(\min )$ & $t_{\mathrm{e}}(\min )$ & $V_{\mathrm{b}}(\mathrm{L})$ & $V_{\mathrm{e}}(\mathrm{L})$ & $\operatorname{MTZ}(\mathrm{cm})$ & $t_{\mathrm{z}}(\min )$ & $U_{\mathrm{z}}(\mathrm{cm} / \mathrm{min})$ & $\operatorname{HUB}(\mathrm{cm})$ & $\begin{array}{l}\text { Percentage } \\
\text { saturation }\end{array}$ \\
\hline 5 & 0.015 & 50 & 70 & 210 & 0.8 & 3.15 & 3.571 & 150 & 0.0238 & 2.842 & 68.80 \\
\hline 10 & 0.015 & 50 & 120 & 260 & 1.9 & 4.05 & 5.926 & 160 & 0.0370 & 4.255 & 73.10 \\
\hline 15 & 0.015 & 50 & 160 & 340 & 2.9 & 5.1 & 7.941 & 180 & 0.0441 & 5.840 & 78.80 \\
\hline 15 & 0.02 & 50 & 90 & 230 & 1.8 & 4.6 & 9.13 & 140 & 0.065 & 6.63 & 72.91 \\
\hline 15 & 0.025 & 50 & 40 & 200 & 1 & 5 & 12.00 & 160 & 0.075 & 10.20 & 65.34 \\
\hline 15 & 0.015 & 100 & 110 & 260 & 1.5 & 3.9 & 9.231 & 160 & 0.0577 & 7.02 & 74.80 \\
\hline 15 & 0.015 & 150 & 60 & 220 & 0.75 & 3.3 & 11.591 & 170 & 0.0682 & 9.65 & 66.20 \\
\hline
\end{tabular}




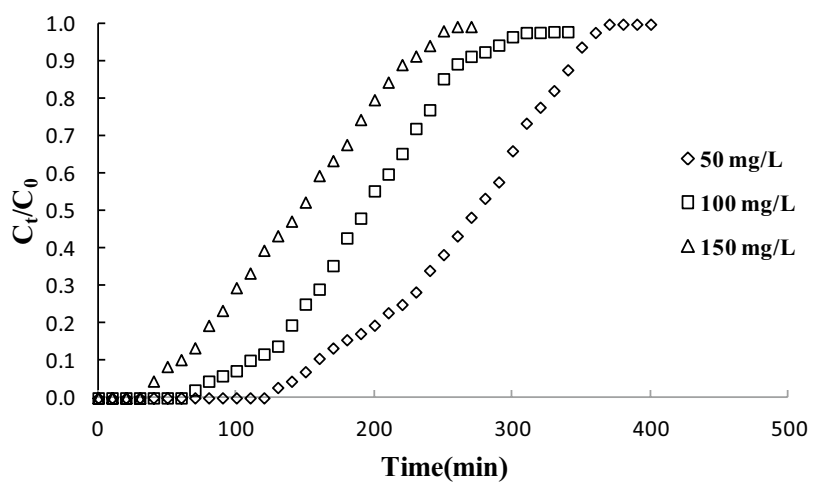

Fig. 3 Effect of influent phenol concentration on the breakthrough curve. (Operating conditions: flow rate $15 \mathrm{~mL} / \mathrm{min}, \mathrm{pH} \mathrm{2}$, bed height $15 \mathrm{~cm})$

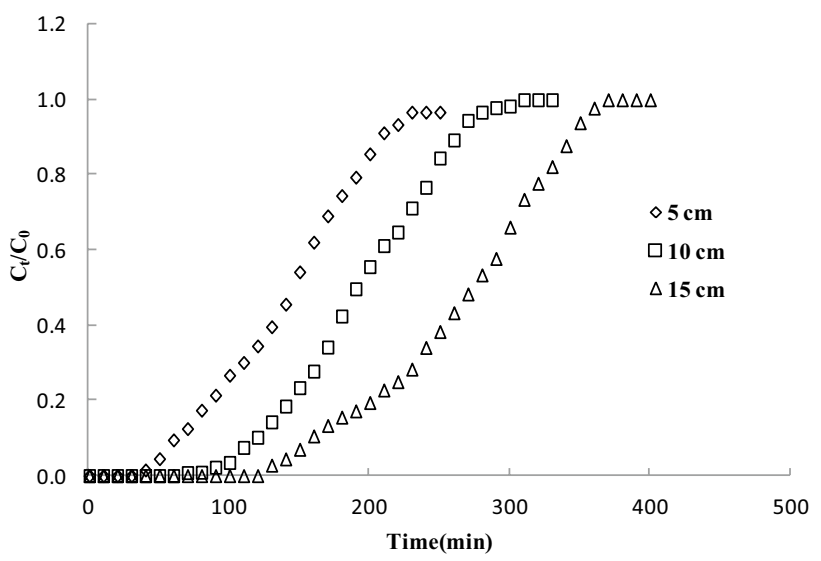

Fig. 4 Effect of bed height on the breakthrough curve. (Operating conditions: phenol concentration $50 \mathrm{mg} / \mathrm{L}$, flow rate $15 \mathrm{~mL} / \mathrm{min}, \mathrm{pH}$ 2)

exhaust time observations indicated that a longer time was required to attain saturation at smaller flow rates. It is understandable considering that at lower flow rates, phenol species have enough time to diffuse through the pores of the adsorbent material and hence occupy more sites. The observations concur with the literature reports [20-22]. Increase in volumetric flow rates in the garlic peel bed showed a decrease in phenol removal efficiency (65.75-55.52\%). It can be attributed to the reduction in contact time between the adsorbate material and the adsorbent species at increased volumetric flow rates. The empty bed contact time decreased on increasing the stream flow rate (Table 1). At lower values of flow rate, the interaction between adsorbate and adsorbent is enhanced resulting in increased diffusion of phenolic species onto the garlic peel powder and hence results in maximum utilization of sorption bed region. The impact is also

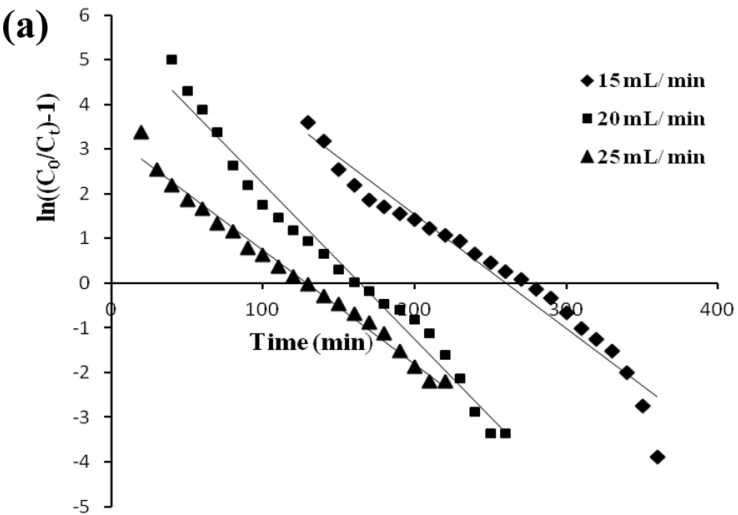

(b)

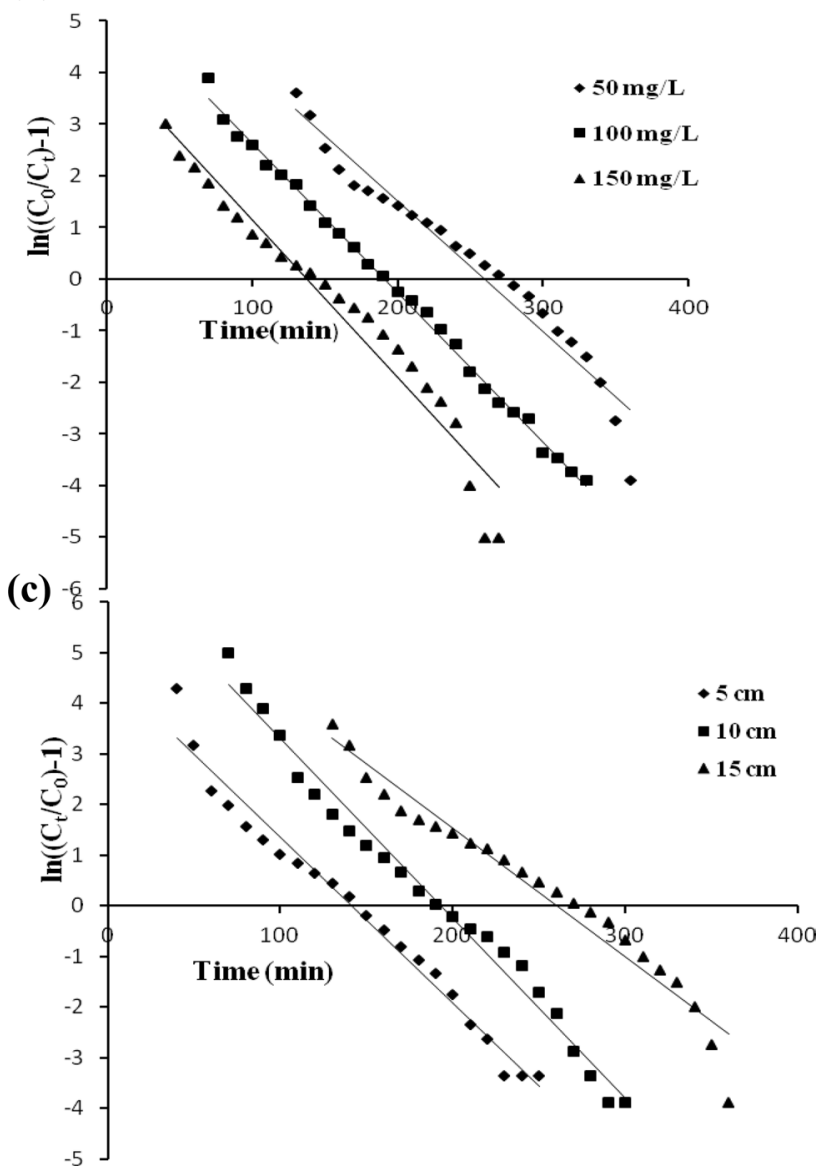

Fig. 5 Linear plot of Thomas model with experimental data at a different flow rates, $\mathbf{b}$ different influent phenol concentrations, and $\mathbf{c}$ different bed heights

reflected in increased longevity in sorption bed performance $[23,24]$. Table 1 also shows the sorption column parameters, namely, length of the mass transfer zone (MTZ), time required for the mass transfer zone to move its own length up or down the column $\left(t_{z}\right)$, and rate of movement of the mass transfer zone $\left(U_{z}\right)$. 


\section{Influence of influent concentration on sorption performance}

Inlet phenol concentration was found to have considerable influence on breakthrough performance (Table 1). The sorption breakthrough curves were plotted based on the experimental data for three distinct feed phenol concentrations: 50,100 and $150 \mathrm{mg} / \mathrm{L}$ with all the other parameters including adsorbent bed height $(15 \mathrm{~cm})$ and volumetric flow rate (15 $\mathrm{mL} / \mathrm{min})$. It was observed that for the phenol composition of 50,100 , and $150 \mathrm{mg} / \mathrm{L}$ in the feed streams, the experimental breakthrough time instants were 160,110 , and $60 \mathrm{~min}$, respectively, and the exhaust time instants were 340 , 260 , and $220 \mathrm{~min}$, respectively. On increasing the incoming phenol concentration from 50 to $150 \mathrm{mg} / \mathrm{L}$, the uptake of sorbent by garlic peel powder increased from 21.15 to $33.46 \mathrm{mg} / \mathrm{g}$, whereas a decrease in phenol percentage removal was observed from 65.70 to $52.72 \%$. The increase in adsorptive capacity of the garlic peel powder was due to higher concentration of phenol in the incoming stream providing higher driving force [25]. As observed in Fig. 3, the lowest inlet phenol composition $(50 \mathrm{mg} / \mathrm{L})$ corresponded to the longest time (160 min) to accomplish the breakthrough, while at the highest phenol composition $(150 \mathrm{mg} / \mathrm{L})$, the breakthrough was achieved relatively quickly $(60 \mathrm{~min})$. The time taken to reach saturation for garlic peel powder adsorbent decreased from 340 to $220 \mathrm{~min}$ when the incoming phenolic concentration increased from 50 to $150 \mathrm{mg} / \mathrm{L}$. For small influent phenolic compositions, the shape of the breakthrough curve was considerably flat signifying a comparatively wider mass transport regime and film-controlled phenomenon. On the other hand, the breakthrough curves were relatively sharper at large phenolic compositions, suggesting a relatively shrunk mass transport regime and intra-particle diffusion-controlled phenomenon. The findings concur with reports from the other researchers [26-28].

\section{Influence of bed height on breakthrough curves}

The breakthrough performance for three distinct heights of GPP bed for phenol-water treatment is illustrated in Fig. 4. It is evident from the Fig. 4 that both the breakthrough and the exhaustion times got extended from 70 to $160 \mathrm{~min}$ and 210 to $340 \mathrm{~min}$, respectively, on increasing sorption bed heights

Table 2 Parameters of the Thomas model at different conditions

\begin{tabular}{|c|c|c|c|c|c|c|c|}
\hline \multicolumn{3}{|c|}{ Operating conditions } & \multicolumn{3}{|c|}{ Parameters of the model } & \multirow[t]{2}{*}{$R^{2}$} & \multirow[t]{2}{*}{ SSE } \\
\hline Flow rate $(\mathrm{L} / \mathrm{min})$ & $\begin{array}{l}\text { Initial concentra- } \\
\text { tion }(\mathrm{mg} / \mathrm{L})\end{array}$ & $\begin{array}{l}\text { Bed height } \\
(\mathrm{cm})\end{array}$ & $K_{\mathrm{Th}}(\mathrm{L} / \mathrm{mg} \min )$ & $q_{\mathrm{e}, \mathrm{cal}}(\mathrm{mg} / \mathrm{g})$ & $q_{\mathrm{e}, \mathrm{exp}}(\mathrm{mg} / \mathrm{g})$ & & \\
\hline 0.015 & 50 & 15 & 0.0005 & 21.09 & 21.36 & 0.9537 & 0.124 \\
\hline 0.02 & 50 & 15 & 0.0007 & 17.77 & 17.66 & 0.9808 & 0.001 \\
\hline 0.025 & 50 & 15 & 0.0008 & 17.48 & 17.29 & 0.9866 & 0.0002 \\
\hline 0.015 & 50 & 15 & 0.00051 & 21.15 & 21.35 & 0.9517 & 0.118 \\
\hline 0.015 & 100 & 15 & 0.00029 & 31.05 & 31.08 & 0.9881 & 0.0001 \\
\hline 0.015 & 150 & 15 & 0.00020 & 33.46 & 34.69 & 0.9524 & 0.121 \\
\hline 0.015 & 50 & 5 & 0.00126 & 17.58 & 17.60 & 0.9735 & 0.012 \\
\hline 0.015 & 50 & 10 & 0.00091 & 16.02 & 16.40 & 0.9771 & 0.002 \\
\hline 0.015 & 50 & 15 & 0.00051 & 22.05 & 21.95 & 0.9541 & 0.123 \\
\hline
\end{tabular}

Table 3 Parameters of the Yoon-Nelson model at different conditions

\begin{tabular}{|c|c|c|c|c|c|c|c|}
\hline \multicolumn{3}{|c|}{ Operating conditions } & \multicolumn{3}{|c|}{ Parameters of the model } & \multirow[t]{2}{*}{$R^{2}$} & \multirow[t]{2}{*}{ SSE } \\
\hline Flow rate (L/min) & $\begin{array}{l}\text { Initial concen- } \\
\text { tration }(\mathrm{mg} / \mathrm{L})\end{array}$ & $\begin{array}{l}\text { Bed } \\
\text { height } \\
(\mathrm{cm})\end{array}$ & $K_{\mathrm{YN}}\left(\min ^{-1}\right)$ & $\tau_{\text {cal }}(\min )$ & $\tau_{\exp }(\min )$ & & \\
\hline 0.015 & 50 & 15 & 0.0255 & 259.7 & 270 & 0.9886 & 0.001 \\
\hline 0.02 & 50 & 15 & 0.0345 & 164.5 & 160 & 0.9990 & 0.0001 \\
\hline 0.025 & 50 & 15 & 0.025 & 129.7 & 130 & 0.9980 & 0.0002 \\
\hline 0.015 & 50 & 15 & 0.0253 & 260.42 & 270 & 0.9911 & 0.0002 \\
\hline 0.015 & 100 & 15 & 0.0289 & 191.16 & 190 & 0.9956 & 0.0002 \\
\hline 0.015 & 150 & 15 & 0.0305 & 137.33 & 140 & 0.9884 & 0.002 \\
\hline 0.015 & 50 & 5 & 0.0328 & 140.49 & 140 & 0.9883 & 0.002 \\
\hline 0.015 & 50 & 10 & 0.0356 & 192.49 & 190 & 0.9885 & 0.002 \\
\hline 0.015 & 50 & 15 & 0.0255 & 259.73 & 270 & 0.9881 & 0.002 \\
\hline
\end{tabular}


from 5 to $15 \mathrm{~cm}$ (Table 1). Furthermore, the volumetric amounts of phenolic solution treated at breakthrough point and exhaust point were higher (Table 1) for the longer bed heights when compared to the shorter ones. The experiments indicated that the saturation was reached faster for shorter beds due to restricted availability of sorbent and hence the availability of active adsorption sites on GPP. The profiles of the breakthrough curves leveled off on increasing bed heights, resulting from a widened mass transfer zone formation. The columns with the longer adsorbent beds, therefore, took a much longer duration to reach complete exhaustion contributing to the extended service time of the beds $[29,30]$.

\section{Modeling and analysis of column adsorption data}

Different existing mathematical models were assessed to elicit information on fixed-bed adsorption column performance and to derive the parameters that would be helpful for scale up of columns for field applications. The models examined included those proposed by Thomas, Yoon-Nelson, Clark, Adams-Bohart, and Wolborska. The goodness of model fit was assessed using the coefficient of determination and the sum of the squares of the errors obtained to through regression analysis.

\section{Application of the Thomas model}

The model proposed by Thomas indicated the highest phenol concentration on GPP solid phase $\left(q_{\mathrm{e}, \text { cal }}\right)$ and adsorption rate constant $\left(K_{\mathrm{Th}}\right)$ for the continuous process. A plot of $\ln \left(\frac{C_{0}}{C_{t}}-1\right)$ versus time for biosorption of phenol on GPP at distinct experimental conditions is shown in Fig. 5. The calculated values of constants $K_{\mathrm{Th}}$ and $q_{\mathrm{e}, \mathrm{cal}}$ as obtained from Eq. (8) along with the statistical information are listed in Table 2. The concentration values $q_{\mathrm{e} \text {,cal }}$ obtained from Thomas model using Eq. (2) were comparable to the experimental values $\left(q_{\mathrm{e}, \exp }\right)$ obtained. The value of $q_{\mathrm{e}, \text { cal }}$ decreased from 21.09 to $17.55 \mathrm{mg} / \mathrm{g}$, as the volumetric flow rate increased from 15 to $25 \mathrm{~mL} / \mathrm{min}$. A higher Thomas model rate constant indicated faster approach to the equilibrium. The adsorptive capacity increased from 21.15 to $33.46 \mathrm{mg} / \mathrm{g}$, as the initial phenolic composition increased from 50 to $150 \mathrm{mg} / \mathrm{L}$, whereas the value of $K_{\mathrm{Th}}$ decreased from 0.00051 to $0.00020(\mathrm{~L} / \mathrm{min} \mathrm{mg})$, respectively, in agreement with trends reported in the literature [31-33]. It is also evident from Table 3 that as $C_{0}$ and GPP quantity increased, the values of $q_{\mathrm{e} \text {,cal }}$ and $K_{\mathrm{Th}}$ saw a corresponding changes. The behavior can be attributed to the fact that the driving force for adsorptive phenomenon is directly determined by the difference in phenolic concentrations in two phases. The value of $R^{2}$ varies from 0.9866 to 0.9517 , while the values of SSE range between 0.0001 and 0.124 . The high values of coefficient of determination and low values of SSE indicate

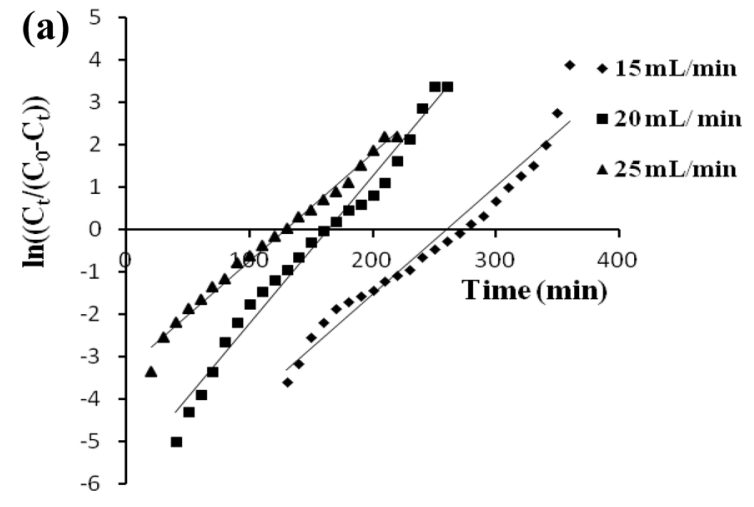

(b)
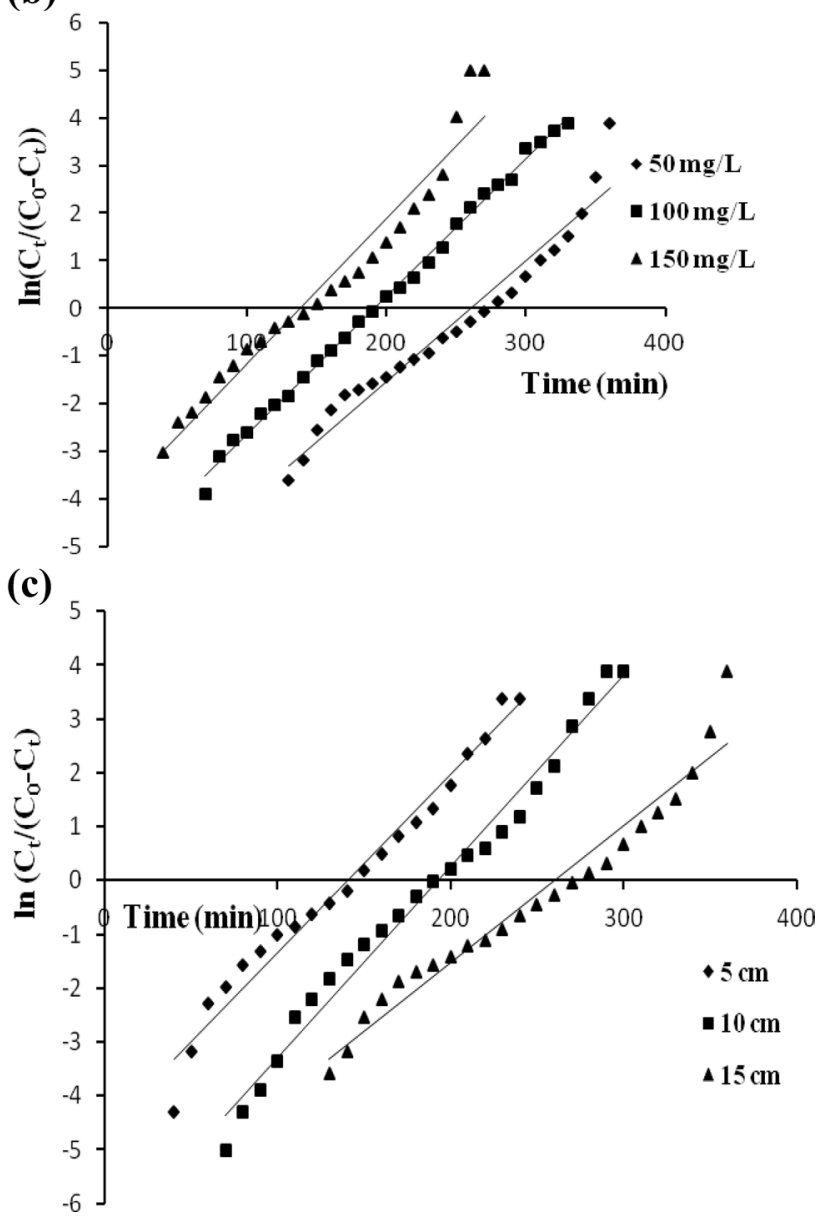

Fig. 6 Linear plot of Yoon-Nelson model with experimental data at a different flow rates, $\mathbf{b}$ different influent phenol concentrations, and $\mathbf{c}$ different bed heights

the goodness of fit between the experimentally collected data and the corresponding predictions made by the model.

\section{Application of the Yoon-Nelson model}

The rate constant in Yoon-Nelson model $K_{\mathrm{YN}}$ decreased, whereas that of $50 \%$ breakthrough time $\tau_{\text {cal }}$ increased as 
Table 4 Parameters of the Clark model at different conditions

\begin{tabular}{|c|c|c|c|c|c|c|c|c|}
\hline \multicolumn{3}{|c|}{ Operating conditions } & \multicolumn{4}{|c|}{ Parameters of the model } & \multirow[t]{2}{*}{$R^{2}$} & \multirow[t]{2}{*}{ SSE } \\
\hline Flow rate (L/min) & $\begin{array}{l}\text { Initial concentra- } \\
\text { tion }(\mathrm{mg} / \mathrm{L})\end{array}$ & $\begin{array}{l}\text { Bed height } \\
(\mathrm{cm})\end{array}$ & $A(-)$ & $r\left(\min ^{-1}\right)$ & $k(\mathrm{~L} / \mathrm{min} \mathrm{mg})$ & $q_{m}(\mathrm{mg} / \mathrm{g})$ & & \\
\hline 0.015 & 50 & 15 & 493.14 & 0.0245 & 0.00049 & 20.56 & 0.9493 & 0.021 \\
\hline 0.02 & 50 & 15 & 190.15 & 0.033 & 0.00066 & 17.22 & 0.9825 & 0.020 \\
\hline 0.025 & 50 & 15 & 19.23 & 0.024 & 0.00048 & 16.61 & 0.9897 & 0.018 \\
\hline 0.015 & 50 & 15 & 478.28 & 0.0244 & 0.00048 & 20.54 & 0.9473 & 0.023 \\
\hline 0.015 & 100 & 15 & 174.83 & 0.0288 & 0.00028 & 29.96 & 0.9964 & 0.0004 \\
\hline 0.015 & 150 & 15 & 37.05 & 0.0297 & 0.00019 & 29.64 & 0.9479 & 0.021 \\
\hline 0.015 & 50 & 5 & 72.20 & 0.0317 & 0.00063 & 31.44 & 0.9789 & 0.025 \\
\hline 0.015 & 50 & 10 & 592.35 & 0.0341 & 0.00068 & 21.90 & 0.9843 & 0.019 \\
\hline 0.015 & 50 & 15 & 493.93 & 0.0245 & 0.00049 & 20.56 & 0.9497 & 0.023 \\
\hline
\end{tabular}

bed depth increased (Table 3). However, with an increase in volumetric flow rates, the values of $\tau_{\text {cal }}$ decreased, but the value of $K_{\text {YN }}$ (Fig. 6) increased. The substantial reduction in $\tau_{\text {cal }}$ value with decreased bed height, increased inflow velocity, and increased incoming phenol concentration was due to fast saturation of fixed-bed columns. Similar patterns of relation between a decrease in $\tau_{\text {cal }}$ and increase in rate constant $K_{\mathrm{YN}}$ on increasing the volumetric flow rate and influent sorbate concentration have been reported in the literature $[34,35]$. Table 3 indicates that the values of $\tau_{\text {cal }}$ estimated by the Yoon-Nelson model are in close agreement with the experimentally determined values $\tau_{\text {exp }}$. The regression coefficient values being high (ranging from 0.9990 to 0.9881 ), as given in the Table 3, and low values of SSE ranging between 0.0002 and 0.002 advocated that Yoon-Nelson model exhibited a good fit to the experimentally determined adsorption data obtained in the present studies.

\section{Application of the Clark model}

The calculations in Clark model were performed with Freundlich constant $n=1.9$. The parameters $r$ and $A$ in the Clark equation were determined from concentration versus time data according to Eq. (10). Table 4 enlists $r$ and $A$ values in the Clark model. The data indicate that the values of $r$ increased with the decrease in bed height, increase in volumetric flow rate and incoming phenol composition. Besides, the values of $A$ also increased with bed height. The model parameters $r$ and $A$ were incorporated into the equation to obtain the concentration terms at various values of time and plotted along with experimentally determined breakthrough curves (Fig. 7). The adsorption rate coefficient $k$ and removal capacity $q_{m}$ were estimated. Regression analysis has indicated the applicability of the model for calculating the parameters [36].

\section{Application of the Adams-Bohart model}

The mathematical approach focused on the estimation of the Adams-Bohart model parameters, including maximum volumetric adsorptive capacity $\left(N_{0}\right)$ and kinetic constant $\left(K_{\text {Adams }}\right)$ from the model equation [37]. The results are presented in Table 5 under various operating conditions along with error analysis parameters, which indicated unsatisfactory fitness. As the initial phenol concentration is increased, the maximum volumetric adsorptive capacity of the bed increased from $3288.0 \mathrm{mg} / \mathrm{L}$ (at $50 \mathrm{mg} / \mathrm{L}$ ) to $5596.9 \mathrm{mg} / \mathrm{L}$ (at $150 \mathrm{mg} / \mathrm{L}$ ). Furthermore, the values of kinetics constant $K_{\text {Adams }}$ increased, as the flow rate increased. However, with the increase in inlet concentration and kinetics constant, $K_{\text {Adams }}$ decreased from $3.60 \times 10^{-3}$ to $1.40 \times 10^{-3} \mathrm{~L} / \mathrm{mg}$ min. Figure 8 shows the predicted and experimental breakthrough curves under optimized conditions. Based on regression analysis results, the Adams-Bohart model is found relatively less suitable for depicting the adsorption behavior of phenol in garlic peel powder.

\section{Application of the Wolborska model}

The phenol remediation data were also fitted using Wolborska model using Eq. (15) for various operating conditions. A linear relationship (Fig. 8) for $\ln \left(C_{0} / C_{t}\right)$ versus time was found for the low concentration regime up to $50 \%$ breakthrough. The linear plot was used to determine the kinetic coefficients of mass transfer and bed capacity $N_{0}$. Table 6 shows the determined parametric values. An increment in volumetric flow rate from 15 to $20 \mathrm{~mL} / \mathrm{min}$ increased the $\beta$ value. It could be attributed to the possible shrinkage in the film boundary layer zone adjacent to the sorbent particles at higher turbulence. $N_{0}$ values increased with increment in the values of $Z$ and $C_{0}$ and decreased with increase in the volumetric flow rates [38]. Error analysis for various models (compiled in Table 7) suggests that the Yoon-Nelson model 

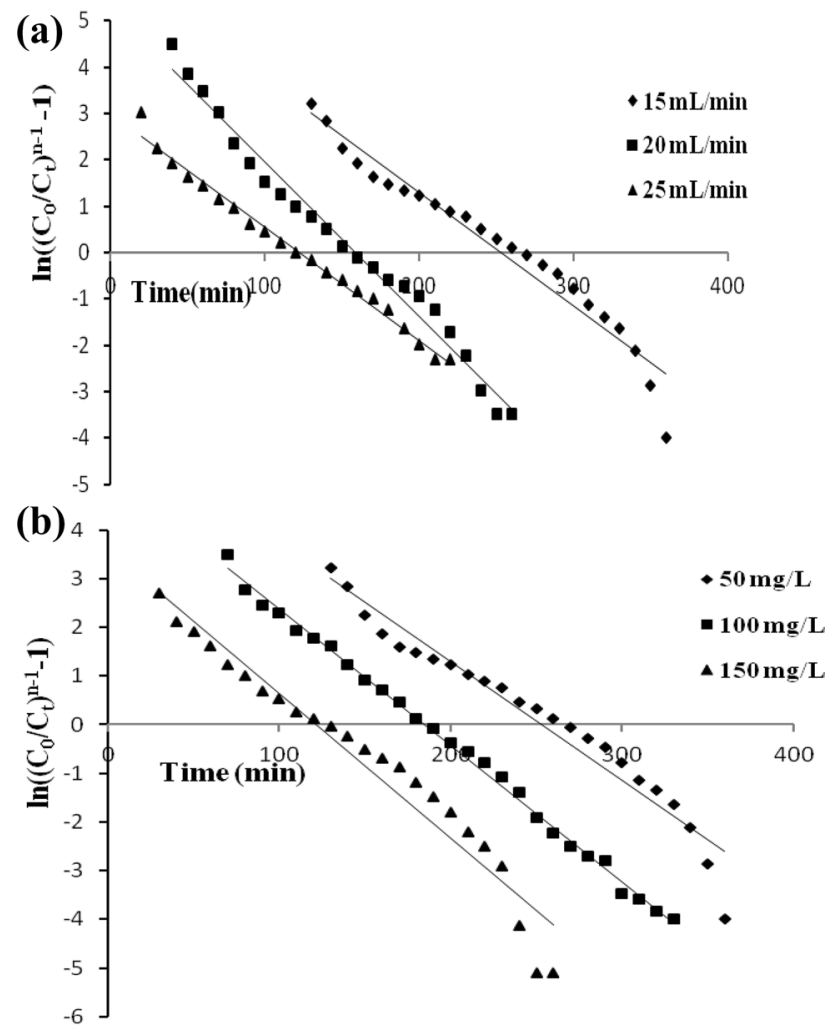

(c)

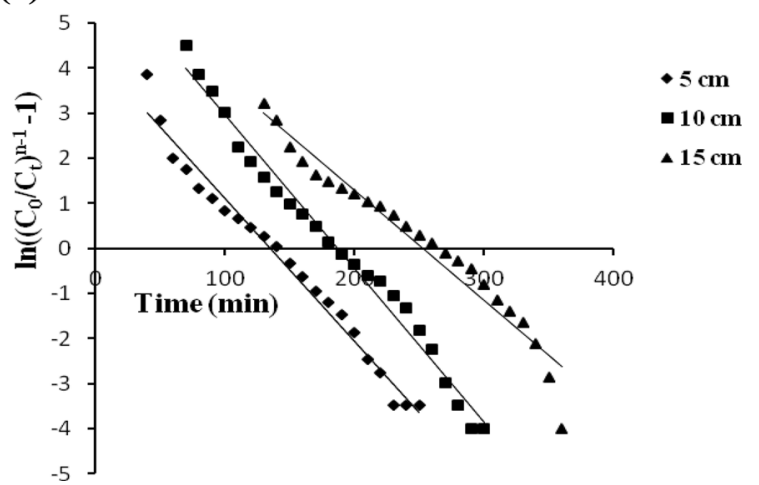

Fig. 7 Linear plot of Clark model with experimental data at a different flow rates, $\mathbf{b}$ different influent phenol concentrations, and $\mathbf{c}$ different bed heights

Table 5 Parameters of the Adams-Bohart model at different conditions
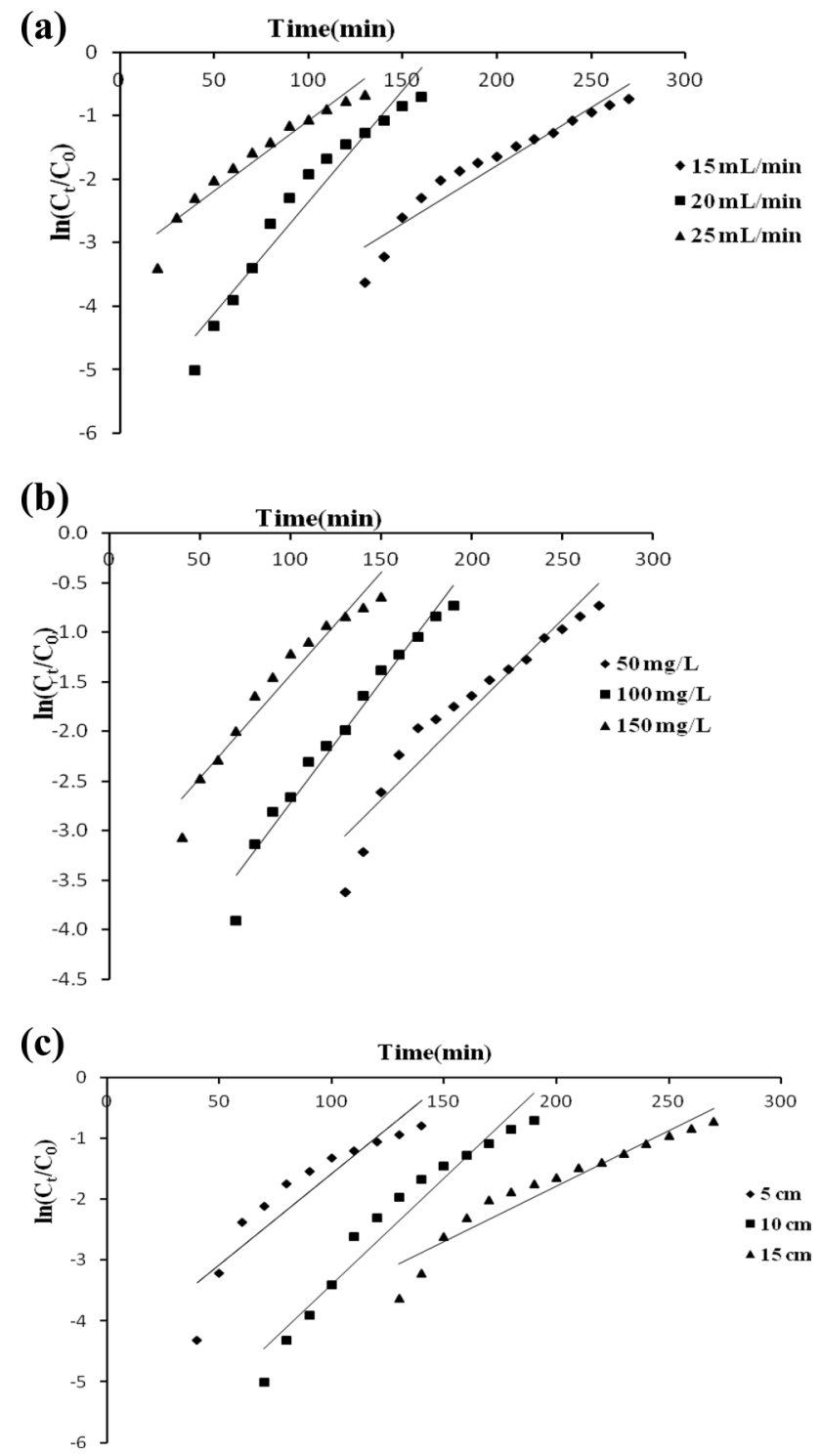

Fig. 8 Linear plot of Adams-Bohart model and Wolborska model with experimental data at a different flow rates, $\mathbf{b}$ different influent phenol concentrations, and $\mathbf{c}$ different bed heights

\begin{tabular}{|c|c|c|c|c|c|c|}
\hline \multicolumn{3}{|c|}{ Operating conditions } & \multicolumn{2}{|c|}{ Parameters of the Model } & \multirow[t]{2}{*}{$R^{2}$. } & \multirow[t]{2}{*}{ SSE. } \\
\hline $\begin{array}{l}\text { Flow rate } \\
(\mathrm{L} / \mathrm{min})\end{array}$ & $\begin{array}{l}\text { Initial concen- } \\
\text { tration }(\mathrm{mg} / \mathrm{L})\end{array}$ & $\begin{array}{l}\text { Bed height } \\
(\mathrm{cm})\end{array}$ & $K_{\text {Adams }}(\mathrm{L} / \mathrm{mg}-\mathrm{min})$ & $N_{0}(\mathrm{mg} / \mathrm{L})$ & & \\
\hline 0.015 & 50 & 15 & 0.0003660 & 3292.48 & 0.9194 & 1.987 \\
\hline 0.02 & 50 & 15 & 0.0007040 & 2457.58 & 0.9463 & 7.015 \\
\hline 0.025 & 50 & 15 & 0.0004420 & 2750.26 & 0.9322 & 2.452 \\
\hline 0.015 & 50 & 15 & 0.00036 & 3288.0 & 0.9121 & 2.022 \\
\hline 0.015 & 100 & 15 & 0.00024 & 4691.1 & 0.9683 & 1.340 \\
\hline 0.015 & 150 & 15 & 0.00014 & 5596.9 & 0.9413 & 4.955 \\
\hline 0.015 & 50 & 5 & 0.0006 & 5061.67 & 0.8459 & 2.101 \\
\hline 0.015 & 50 & 10 & 0.0004 & 3267.55 & 0.9445 & 6.590 \\
\hline 0.015 & 50 & 15 & 0.00037 & 3297.04 & 0.9205 & 2.035 \\
\hline
\end{tabular}


Table 6 Parameters of the Wolborska model at different conditions

\begin{tabular}{|c|c|c|c|c|c|c|}
\hline \multicolumn{3}{|c|}{ Operating conditions } & \multicolumn{2}{|c|}{ Parameters of the model } & \multirow[t]{2}{*}{$R^{2}$} & \multirow[t]{2}{*}{ SSE } \\
\hline Flow rate $(\mathrm{L} / \mathrm{min})$ & $\begin{array}{l}\text { Initial concentra- } \\
\text { tion }(\mathrm{mg} / \mathrm{L})\end{array}$ & $\begin{array}{l}\text { Bed height } \\
(\mathrm{cm})\end{array}$ & $N_{0}(\mathrm{mg} / \mathrm{L})$ & $\beta\left(\min ^{-1}\right)$ & & \\
\hline 0.015 & 50 & 15 & 3292.48 & 1.21 & 0.9194 & 2.020 \\
\hline 0.02 & 50 & 15 & 2457.58 & 1.73 & 0.9463 & 9.30 \\
\hline 0.025 & 50 & 15 & 2750.26 & 1.92 & 0.9322 & 2.000 \\
\hline 0.015 & 50 & 15 & 3288.0 & 1.2 & 0.9121 & 1.777 \\
\hline 0.015 & 100 & 15 & 4691.1 & 1.14 & 0.9683 & 1.964 \\
\hline 0.015 & 150 & 15 & 5596.9 & 0.78 & 0.9413 & 4.858 \\
\hline 0.015 & 50 & 5 & 5061.67 & 3.04 & 0.8459 & 2.236 \\
\hline 0.015 & 50 & 10 & 3267.55 & 2.29 & 0.9445 & 6.223 \\
\hline 0.015 & 50 & 15 & 3297.04 & 1.21 & 0.9205 & 1.970 \\
\hline
\end{tabular}

Table 7 Error analysis for various models

\begin{tabular}{|c|c|c|c|c|c|c|c|c|c|c|c|c|}
\hline \multicolumn{3}{|c|}{ Operating conditions } & \multicolumn{2}{|c|}{ Thomas model } & \multicolumn{2}{|c|}{$\begin{array}{l}\text { Yoon-Nelson } \\
\text { model }\end{array}$} & \multicolumn{2}{|c|}{ Clark model } & \multicolumn{2}{|c|}{$\begin{array}{l}\text { Adams-Bohart } \\
\text { model }\end{array}$} & \multicolumn{2}{|c|}{$\begin{array}{l}\text { Wolborska } \\
\text { model }\end{array}$} \\
\hline Flow rate $(\mathrm{L} / \mathrm{min})$ & $\begin{array}{l}\text { Initial } \\
\text { Conc. } \\
\text { (mg/L) }\end{array}$ & Bed ht. (cm) & $R^{2}$ & SSE & $R^{2}$ & SSE & $R^{2}$ & SSE & $R^{2}$ & SSE & $R^{2}$ & SSE \\
\hline 0.015 & 50 & 15 & 0.9537 & 0.124 & 0.9886 & 0.002 & 0.9493 & 0.021 & 0.9194 & 1.987 & 0.9194 & 2.020 \\
\hline 0.02 & 50 & 15 & 0.9808 & 0.0001 & 0.9990 & 0.0002 & 0.9825 & 0.020 & 0.9463 & 7.015 & 0.9463 & 9.30 \\
\hline 0.025 & 50 & 15 & 0.9880 & 0.0002 & 0.9980 & 0.002 & 0.9897 & 0.018 & 0.9322 & 2.452 & 0.9322 & 2.000 \\
\hline 0.015 & 50 & 15 & 0.9517 & 0.118 & 0.9911 & 0.0002 & 0.9473 & 0.023 & 0.9121 & 2.022 & 0.9121 & 1.777 \\
\hline 0.015 & 100 & 15 & 0.9881 & 0.001 & 0.9956 & 0.0002 & 0.9964 & 0.0004 & 0.9683 & 1.340 & 0.9683 & 1.964 \\
\hline 0.015 & 150 & 15 & 0.9524 & 0.121 & 0.9884 & 0.002 & 0.9479 & 0.021 & 0.9413 & 4.955 & 0.9413 & 4.858 \\
\hline 0.015 & 50 & 5 & 0.9735 & 0.012 & 0.9883 & 0.002 & 0.9789 & 0.025 & 0.8459 & 2.101 & 0.8459 & 2.236 \\
\hline 0.015 & 50 & 10 & 0.9771 & 0.002 & 0.9885 & 0.002 & 0.9843 & 0.019 & 0.9445 & 6.590 & 0.9445 & 6.223 \\
\hline 0.015 & 50 & 15 & 0.9541 & 0.126 & 0.9881 & 0.002 & 0.9497 & 0.023 & 0.9205 & 2.035 & 0.9205 & 1.970 \\
\hline
\end{tabular}

is the most suitable for the prediction of breakthrough curves at the experimental conditions studied for phenol sorption in GPP columns.

\section{Conclusion}

The studies have indicated that the process of removal of phenol from aqueous systems using garlic peel powder can be successfully translated to the field, as the removal is possible in continuous mode. Furthermore, it indicated that low flow rates would sustain the performance for a longer time within breakthrough levels with a higher specific rate of adsorption improving the efficiency of utilization of garlic peels. This would be advantageous, as garlic peel adsorption is a once-through process without regeneration. The various models of adsorption were assessed using the experimental data and specific information were derived: adsorption capacity (Thomas), 50\% breakthrough (Yoon-Nelson), removal rate (Clark) and maximum volumetric adsorption capacity (Adams-Bohart) and kinetic coefficient of mass transfer (Wolborska). It is inferred that the fixed-bed adsorption column with GPP adsorbent can be used as a phenol remediation technique for aqueous streams. The insights gained here from experimental column studies would aid in the design and scale up of phenol sorption GPP columns for utility in field applications.

Open Access This article is distributed under the terms of the Creative Commons Attribution 4.0 International License (http://creativecommons.org/licenses/by/4.0/), which permits unrestricted use, distribution, and reproduction in any medium, provided you give appropriate credit to the original author(s) and the source, provide a link to the Creative Commons license, and indicate if changes were made.

\section{References}

1. Lua AC, Jia Q (2009) Adsorption of phenol by oil-palm-shell activated carbons in a fixed bed. Chem Eng J 150:455-461

2. Busca G, Berardinelli S, Resini C, Arrighi L (2008) Technologies for the removal of phenol from fluid streams: a short review of recent developments. J Hazard Mater 160:265-288 
3. Karthik V, Sivarajasekar N, Padmanaban VC, Nakkeeran E, Selvaraju N (2018) Biosorption of xenobiotic reactive black B onto metabolically inactive T. Harzianum biomass: optimization and equilibrium studies. Int J Environ Sci Technol. https://doi. org/10.1007/s13762-018-1841-5

4. Muazu ND, Jarrah N, Zubair M, Alagha O (2017) Removal of phenolic compounds from water using sewage sludge-based activated carbon adsorption: a review. Int J Environ Res Public Health $14: 2-34$

5. Nakkeeran E, Selvaraju N (2017) Biosorption of chromium (VI) in aqueous solutions by chemically modified strychnine tree fruit shell. Int J Phytoremediation 19:1065-1076

6. Anisuzzaman SM, Joseph CG, Wan Daud WMAB, Krishnaiah D, Yee HS (2015) Preparation and characterization of activated carbon from Typha orientalis leaves. Int J Ind Chem 6:9-21

7. Abhishek A, Saranya N, Chandi P, Selvaraju N (2018) Studies on the remediation of chromium (VI) from simulated wastewater using novel biomass of Pinus kesiya cone. Desalin Water Treat 114:192-204

8. Ahmad T, Danish M, Rafatullah M, Ghazali A, Sulaiman O, Hashim R, Ibrahim MNM (2012) The use of date palm as a potential adsorbent for wastewater treatment: a review. Environ Sci Pollut Res 19:1464-1484

9. Mohammad SG, Ahmed SM (2017) Preparation of environmentally friendly activated carbon for removal of pesticide from aqueous media. Int J Ind Chem 8:121-132

10. Ahmad T, Rafatullah M, Ghazali A, Sulaiman O, Hashim R (2011) Oil palm biomass-based adsorbents for the removal of water pollutants-a review. J Environ Sci Health C 29:177-222

11. Hameed BH, Ahmad AA (2009) Batch adsorption of methylene blue from aqueous solution by garlic peel, an agricultural waste biomass. J Hazard Mater 164:870-875

12. Ichikawa M, Ryu K, Yoshida J, Ide N, Kodera Y, Sasaoka T, Rosen RT (2003) Identification of six phenylpropanoids from garlic skin as major antioxidants. J Agric Food Chem 51:7313-7317

13. Muthamilselvi P, Karthikeyan R, Kumar BSM (2016) Adsorption of phenol onto garlic peel: optimization, kinetics, isotherm, and thermodynamic studies. Desalin Water Treat 57:2089-2103

14. Jeffery GH, Bassett J, Mendham J, Denney RC (1989) Vogel's textbook of quantitative chemical analysis, 5th edn. Wiley, New York, pp 257-260

15. Bharathi KS, Ramesh SPT (2013) Fixed-bed column studies on biosorption of crystal violet from aqueous solution by Citrullus lanatus rind and Cyperus rotundus. Appl Water Sci 3:673-687

16. Calero M, Hernáinz F, Blázquez G, Tenorio G, Martín-Lara MA (2009) Study of Cr(III) biosorption in a fixed-bed column. J Hazard Mater 171:886-893

17. Han R, Wang Y, Zhao X, Wang Y, Xie F, Cheng J, Tang M (2009) Adsorption of methylene blue by phoenix tree leaf powder in a fixed-bed column: experiments and prediction of breakthrough curves. Desalination 245:284-297

18. Saadi Z, Saadi R, Fazaeli R (2013) Fixed-bed adsorption dynamics of $\mathrm{Pb}$ (II) adsorption from aqueous solution using nanostructured $\gamma$-alumina. J Nanostrut Chem 48:1-8

19. Preetha B, Viruthagiri T (2007) Batch and continuous biosorption of chromium (VI) by rhizopus arrhizus. Sep Purif Technol 57:126-133

20. Padmesh TVN, Vijayaraghavan K, Sekaran G, Velan M (2006) Biosorption of acid blue 15 using fresh water macroalga azolla filiculoides: batch and column studies. Dyes Pigm 71:77-82

21. Sadaf S, Bhatti HN (2014) Batch and fixed bed column studies for the removal of Indosol Yellow BG dye by peanut husk. J Taiwan Inst Chem Eng 45:541-553

22. Chen N, Zhang Z, Feng C, Li M, Chen R, Sugiura N (2011) Investigations on the batch and fixed-bed column performance of fluoride adsorption by Kanuma mud. Desalination 268:76-82
23. Jang J, Lee DS (2016) Enhanced adsorption of cesium on PVAalginate encapsulated prussian blue-graphene oxide hydrogel beads in a fixed-bed column system. Bioresour Technol 218:294-300

24. Sotelo JL, Ovejero G, Rodriguez A, Alvarez S, Garcia J (2013) Adsorption of carbamazepine in fixed bed columns: experimental and modeling studies. Sep Sci Technol 48:2626-2637

25. Anisuzzaman SM, Bono A, Krishnaiah D, Tan YZ (2016) A study on dynamic simulation of phenol adsorption in activated carbon packed bed column. J King Saud Univ Sci 28:47-55

26. Girish CR, Ramachandra Murty V (2015) Adsorption of phenol from aqueous solution using lantana camara, forest waste: packed bed studies and prediction of breakthrough curves. Environ Process 2:773-796

27. Jung KW, Jeong TU, Choi JW, Ahn KH, Lee SH (2017) Adsorption of phosphate from aqueous solution using electrochemically modified biochar calcium-alginate beads: batch and fixed-bed column performance. Bioresour Technol 244:23-32

28. Golie WM, Upadhyayula S (2016) Continuous fixed-bed column study for the removal of nitrate from water using chitosan/alumina composite. J Water Process Eng 12:58-65

29. Mohan S, Singh DK, Kumar V, Hasan SH (2017) Modelling of fixed bed column containing graphene oxide decorated by $\mathrm{MgO}$ nanocubes as adsorbent for lead (II) removal from water. J Water Process Eng 17:216-228

30. Song ST, Hau YF, Saman N, Johari K, Cheu SC, Kong H, Mat H (2016) Process analysis of mercury adsorption onto chemically modified rice straw in a fixed-bed adsorber. J Environ Chem Eng 4:1685-1697

31. Deng H, Li Y, Wu L, Ma X (2017) The novel composite mechanism of ammonium molybdo phosphate loaded on silica matrix and its ion exchange breakthrough curves for cesium. J Hazard Mater 324:348-356

32. Ahmed MJ, Hameed BH (2018) Removal of emerging pharmaceutical contaminants by adsorption in a fixed bed column: a review. Ecotoxicol Environ Saf 149:257-266

33. Nakkeeran E, Patra C, Shahnaz T, Rangabhashiyam S, Selvaraju N (2018) Continuous biosorption assessment for the removal of hexavalent chromium from aqueous solutions using Strychnos nux vomica fruit shell. Bioresour Technol R 3:256-260

34. Mohan S, Kumar Singh D, Kumar V, Hasan SH (2017) Effective removal of fluoride ions by $\mathrm{rGO} / \mathrm{ZrO}_{2}$ nanocomposite from aqueous solution: Fixed bed column adsorption modelling and its adsorption mechanism. J Fluorine Chem 194:40-50

35. El-Naas MH, Alhaija MA, Al-Zuhair S (2017) Evaluation of an activated carbon packed bed for the adsorption of phenols from petroleum refinery wastewater. Environ Sci Pollut Res Int 24:7511-7520

36. Li C, Xu M, Sun X, Han S, Wu X, Liu NY, Huang J, Deng S (2013) Chemical modification of Amberlite XAD-4 by carbonyl groups for phenol adsorption from wastewater. Chem Eng $\mathrm{J}$ 229:20-26

37. Lin X, Li R, Wen Q, Wu J, Fan J, Jin X, Qian W, Liu D, Chen X, Chen Y, Xie J, Bai J, Ying H (2013) Experimental and modeling studies on the sorption breakthrough behaviors of butanol from aqueous solution in a fixed bed of KA- I resin. Biotechnol Bioprocess Eng 8:223-233

38. Pal S, Mukherjee S, Ghosh S (2013) Nonlinear kinetic analysis of phenol adsorption onto peat soil. Environ Earth Sci 71:2564-2565

Publisher's Note Springer Nature remains neutral with regard to jurisdictional claims in published maps and institutional affiliations. 